\title{
MAXILLOFACIAL FRACTURES; \\ ASSESSMENT OF CONCOMITANT INJURIES \\ drsunilpanjabi@yahoo.com
}

1. BDS, FCPS

Assistant Professor

Oral \& Maxillofacial Surgery

Department

Faculty of Dentistry,

LUMHS, Jamshoro

2. MBBS, FCPS

Associate Professor

Department of General Surgery

LUMHS, Jamshoro

3. MBBS, MS

Assistant Professor

Department of Neuro Surgery

LUMHS, Jamshoro

4. BDS, (MSc- Trainee)

Department of Community Dentistry

Faculty of Dentistry,

LUMHS, Jamshoro

Correspondence Address:

Dr. Suneel Kumar Punjabi

Flat No: $3073^{\text {rdfloor Citizen Plaza }}$

Opp Aga Khan Hospital

Main Jamshoro Road, Qasimabad,

Hyderabad

drsunilpanjabi@yahoo.com

Article received on:

10/08/2016

Accepted for publication:

15/10/2016

Received after proof reading:

00/00/2016

\section{INTRODUCTION}

There has consistently been an unusual augmentation of human preface to influential operators, assemble them active center of different type of injury, including maxillofacial fractures. Facial trauma have a multiple etiologic factors, i.e. lane auto collisions ${ }^{1}$, where bike accidents are massive sectors ${ }^{2}$, sports injuries ${ }^{3,4}$, interpersonal savagery ${ }^{5,6}$, fall from heights. ${ }^{7,8}$

Due to ecological, social \& financial variables, causes of facial trauma differ around the globe, ${ }^{9}$ consequently epidemiological surveys are used to smash the incidence \& pattern of etiology, seriousness \& recurrence of maxillofacial and dental injury. ${ }^{10}$ In Europe, Portugal has increased prevalence of injury incident \& death rate. As in the 2010 Statistical Year book of Portugal (from the institute of National Statistics), a summation

\begin{abstract}
Dr. Suneel Kumar Punjabi', Dr. Altaf Ahmed Talpur², Dr. Abdul Rauf Memon ${ }^{3}$, Dr. Priya ${ }^{4}$
ATRAC... Background: The incidence of maxillofacial fractures is greater in Pakistan The Design: Descriptive case series. Setting: The department of Emergency and Oral \& Maxillofacial Surgery, Liaquat University of Medical and Health Sciences, Jamshoro. Period: Jan 2014 to Dec more injuries $359(73.40 \%)$ occurs among the age of $20-39$ years. The mainly documented and sports injury was $(2.87 \%)$. With respect to related injuries, a sum of 48 patients introduced head injuries and other concomitant injuries. The most common fracture noted was mandible (13.29\%), Naso-orabital ethmoid fractures was $44(8.99 \%)$, majority of patients $186(38.0 \%)$ $(7.9 \%)$ in night, regarding the day's most patients came on first working day that was Saturday $142(29.0 \%)$. Regarding hospital mortality, 11 (2.2\%) people died within less than two days after admittance. Conclusion: The results of this study may support the oral surgeons to rule out other injuries at the time of primary survey and may have a key role in awareness of individuals
\end{abstract} Key words: Concomitant, Assessment, Poly trauma, Mortality

Article Citation: Punjabi SK, Talpur AA, Memon AR, Priya. Maxillofacial fractures; assessment of concomitant injuries. Professional Med J 2016;23(11):1541-1545. DOI: $10.17957 / T P M J / 16.3572$

of 35,426 road auto collisions were traced, 424 of them were lethal. ${ }^{11} \mathrm{~A}$ few written researches regarding modern nations reveal that hit/strike as another factual reason. ${ }^{12}$ The face presumes a critical part in the in the body \& consequently is prone to strikes, which commonly fetch hopeless troubles \& deformation. ${ }^{13}$

Apart from facial fractures, the occurrence of concomitant fractures of others bones of body is important to be considered e.g. cranium, upper \& lower limb injuries, chest injuries \& pelvic bone injuries can happen beside facial injuries. They are subject to injury from high \& low energy blow from RTAs, falls, sports, assaults, etc, \& almost every age groups are subjected to it. ${ }^{14}$ Multiple fractures pattern serves as neuro- protective function, permitting indulgence of energy as a result transmission of fewer lingering injury to 
skull. ${ }^{15}$

Total injuries of human frame were accounts for $9 \%$ of world death $\& 12 \%$ of world load of disease in year 2000. ${ }^{16}$

The reason for this 2-year study was to investigate the facial fractures associated with other skeletal injuries treated at the Emergency \& Oral \& Maxillofacial department of Liaquat University Hospital, Hyderabad, with particular accentuation on age, assorted qualities and occurrence.

\section{MATERIAL AND METHODS}

This descriptive cross sectional survey was carried out in department of Emergency and Oral \& Maxillofacial Surgery, Liaquat University Hospital Hyderabad

Total 489 patients were enrolled in this study from Jan 2014 to Dec 2015.

All the patients presenting in emergency room or directly at Oral \& Maxillofacial Surgery department with trauma were examined by team members.

Maxillofacial fractures alone or in combination with other fractures of body were integrated in this survey. A complete history was taken from the patient or the attendant \& questionnaire filled for every patient. At least two diagnostic radiographs Plane X-rays i.e. Orthopantomogram (OPG), postero-anterior view face, paranasal sinus view (PNS), right and left lateral oblique view of the mandible) was done for each case \& advance imaging like computed tomography (CT scan) was taken wherever required.

Related injuries were included as head, thorax, cervical, spinal, lumbar, stomach, pelvic, upper \& lower appendages, where as fracture of face $s$ were assembled into maxillary, NOE, zygomatic bone, mandible and dentoalveolar.

Data were analyzed in SPSS version 20.0. The frequency and percentages was computed for qualitative variables, like gender, causes, \& associated injuries. Mean \pm standard deviation was computed for qualitative variables, like age. No inferential test was applied because of descriptive statistics.

\section{RESULTS}

Table 1 encloses point of attention on the patients. The age range reach over from 20 to 60 years with mean age, SD $32.43 \pm 4.5$ years. The common male-female ratio was $2.5: 1$.

More injuries 359 (73.40\%) occurred among the age of 20-39 year age. Mainly documented etiologic factor for injury was RTA with $69.38 \%$, followed by assault (16.76\%), fall (11.04\%) and sports injury was (2.87\%). As shown in table-l.

\begin{tabular}{|l|c|c|}
\hline Baseline characteristics & Number & Percentage \\
\hline \begin{tabular}{l|c} 
Age in years, Mean + SD \\
(Range)
\end{tabular} & $\begin{array}{c}32.43 \pm \\
4.5 \text { years }\end{array}$ & \\
\hline & & \\
Age in groups & 197 & $40.20 \%$ \\
20 to 30 & 162 & $33.20 \%$ \\
31 to 40 & 81 & $16.56 \%$ \\
41 to 50 & 49 & $10.02 \%$ \\
\hline 51 to 60 & & \\
\hline Mode of injury & 339 & $69.32 \%$ \\
RTA & 82 & $16.76 \%$ \\
Assault & 54 & $11.04 \%$ \\
Fall & 14 & $02.87 \%$ \\
\hline Sports & \\
\hline Table-I. Baseline characteristics of patients $(n=489)$ \\
\hline
\end{tabular}

With respect to associated injuries, a sum of 48 patients introduced head injuries and other concomitant injuries as described in Figure-1.

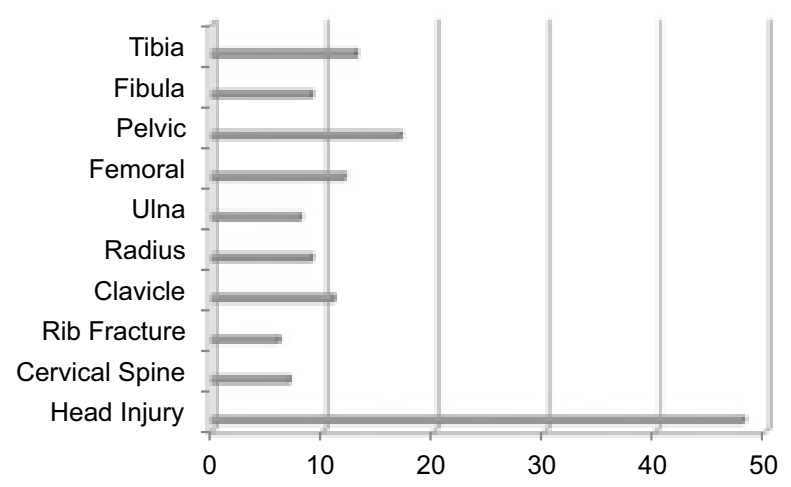

Figure-1. Distribution of Concomitant Injuries

A total of 489 patients with maxillofacial fractures were inspected. In this most common fracture 
noted was mandible 296 (60.53) followed by maxillary fractures 191 (39\%), Zygomatic bone complex fractures 65 (13.29\%), Naso-orabital ethmoid fractures was $44(8.99 \%)$ as shown in Figure-2.

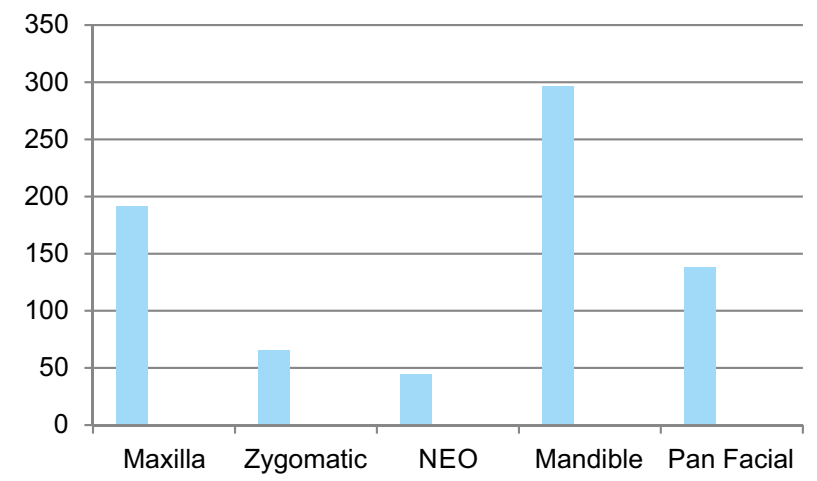

Figure-2. Distributions of Maxillofacial Injuries

Among the 489 patients, majority of patients 186 $(38.0 \%)$ were arrived in morning time followed by 176 (35.9\%) in evening, 88 (17.9\%) in afternoon and $39(7.9 \%)$ in night, regarding the day's most patients came on first working day that was Saturday 142 (29.0\%). Regarding hospital mortality, $11(2.2 \%)$ people died within less than two days after admittance. As shown in table-Il.

\begin{tabular}{|l|c|c|}
\hline \multicolumn{1}{|c|}{ Parameters } & Number & Percentage \\
\hline Hospital arrival & & \\
Morning & 186 & $38.0 \%$ \\
Afternoon & 88 & $17.9 \%$ \\
Evening & 176 & $35.9 \%$ \\
Night & 39 & $7.9 \%$ \\
\hline Days & & \\
Saturday & 142 & $29.0 \%$ \\
Sunday & 34 & $6.95 \%$ \\
Monday & 93 & $19.0 \%$ \\
Tuesday & 39 & $7.9 \%$ \\
Wednesday & 44 & $8.9 \%$ \\
Thursday & 93 & $19.0 \%$ \\
Friday & 44 & $8.9 \%$ \\
\hline Mortality & 11 & $2.2 \%$ \\
\hline
\end{tabular}

Table-II. Distribution of patients according to time, day and mortality

\section{DISCUSSION}

Epidemiologically, the degree of patients with facial trauma is similar to those of diverse genuine multi-injuries. Present survey ascertains 48 (34\%) patients with cranium injury \& concluded to have severe head injuries \& a summation of 11 (2.2\%) people didn't survive. A research done by Zandi $\mathrm{M}$ et al, in which $23.3 \%$ patients have skull injuries related to facial fractures and the frequent cranium injury type was concussion, followed by cerebral contusion and skull fractures, ${ }^{17}$ and study conducted by Grant Al clearly indicated Incidence of brain injury was $67 \%$ overall which is not similar with results of our study. ${ }^{18}$

It is hard to separate the mortality \& dreadfulness of maxillofacial fractures associated with it. The overriding parts of disseminated studies have shown high proportion in adolescent. ${ }^{18}$

In current study, congregation in the age of 20-39 years was the mainly subjective of maxillofacial injury but in a equivalent study, the author told similar characteristics, with the a good number as often as probable predisposed age congregation being $21-30$ years. ${ }^{19,20,21}$

The etiology of maxillofacial \& concomitant injuries in our study results clearly indicated RTA was the widespread causative factor followed by assaults, which were similar with the studies conducted in different parts of world. 15,19,22,23

Maxillofacial injuries are barely fatal; however these injuries certainly cause physical/ psychological stress to the patient. ${ }^{16}$

Maxillofacial injuries might comprise upper third, middle third, and/or lower third of the face, inclusive or exclusive of soft tissue injury \& most of the times dentition possibly will also have injuries i.e. extrusion, intrusion, luxation or tooth crown fracture. Mainly, common site of fracture is mandible followed by maxilla, isolated zygomatic bone and nasal bone amongst maxillofacial injuries. The basis for mandible fracture to be most frequent is because of its position; prominence \& mobility. Similar findings were found in the present study with mandible being involved in $60.5 \%$ of the patients, and these results similar with the studies done by Khan $\mathrm{M}$ et al, Ahmed $\mathrm{S}$ et al, Premchand $\mathrm{P}$ et al, and Ahmed S et al. ${ }^{15,19,24,25}$ 
Beside facial injuries, it is imperative to diagnose concomitant injuries \& classify six organ systems associated to these problems: (1) brain, (2) chest, (3) spine (4) abdomen, (5) pelvis, (6) limbs. There are significant statistical variation in the incidence of injuries allied amongst gender, age group, trauma mechanism, \& kind of fracture. The mechanism of these injuries might be via automobile accidents, falls, sports, interpersonal violence \& victims strike with matter. ${ }^{26}$

Hands \& arms are generally used by patients during trauma as defense against facial injuries, whereas thorax \& legs are typically directly impacted in car accidents or falls. ${ }^{26}$

Accident capable to fracture facial skeleton is also expected to have velocity \& allocation of causing other injuries in the body i.e. limbs. The relationship of lower extremities fractures compared to upper extremities was often implicated. comparable results were achieved by Premchand $\mathrm{P}$ et $\mathrm{al}^{24}$, Thoren $\mathrm{H}$ et $\mathrm{al}^{27}$ and Khan $\mathrm{M}$ et $\mathrm{al}^{15}$ Beogo $\mathrm{R}$ et $\mathrm{al}^{28}$ nonetheless this is not sustained by different other international and national studies which illustrate that limb fractures are not as much coupled with maxillofacial injuries. This summit to the truth; that was depends upon related injury type \& differs with variation in blow and etiology of trauma. ${ }^{29,30}$

\section{CONCLUSION}

In conclusion, current survey provides pertinent information on patterns of maxillofacial related with other skeletal injuries in explicit inhabitants \& plays a part in numerous morbidity \& mortality cases. The results of this study may support the oral surgeons to rule out other injuries at the time of primary survey and may have a key role in awareness of individuals in prevention of road traffic accidents.

\section{Copyright@ 15 Oct, 2016.}

\section{REFERENCES}

1. Peden M, Scurfield R, Sleet D, Mohan D, Hyden AA, Jarawan E, et al., editors. World Report on Road Traffic Injury Prevention. Geneva: WHO, 2004.

2. Momeni $H$, Shahnaseri S, Hamzeheil Z. Distribution assessment of maxillofacial fractures in trauma admitted patients in Yazd hospitals: An epidemiologic study. Dent Res J. 2011; 8:80-83.

3. Roccia F, Boffano P, Bianchi FA, Gerbino G. Maxillofacial injuries due to work-related accidents in the North West of Italy. Oral Maxillo Surg 2012; 7:181-186.

4. Elhammali N, Bremerich A, Rustemeyer J. Demographical and clinical aspects of sports-related maxillofacial and skull base fractures in hospitalized patients. Int J Oral Maxillofac Surg 2010; 39:857-862.

5. Shahim FN, Cameron P, McNeil JJ. Maxillofacial trauma in major trauma patients. Australian Dent $\mathrm{J}$. 2006; 51:225-230.

6. Businger AP, Krebs J, Schaller B, Zimmermann $H$, Exadaktylos AK. Cranio-maxillofacial injuries in victims of interpersonal violence. Swiss Med Wkly 2012; 142.

7. Turégano-Fuentes F, Caba-Doussoux P, Jover-Navalón JM, Martín-Pérez E, et al. Injury patterns from major urban terrorist bombings in trains: the Madrid experience. World J Surg 2008; 32:1168-1175.

8. Levin L, Zadik Y, Peleg K, Bigman G, Givon A, Lin S. Incidence and severity of maxillofacial injuries during the Second Lebanon War among Israeli soldiers and civilians. J Oral Maxillofac Surg 2008; 66:1630-1633.

9. Mock C, Quansah R, Krishnan R, Arreola-Risa C, Rivara F. Strengthening the prevention and care of injuries worldwide. Lancet. 2004; 363:2172- 2179.

10. Gassner R, Tuli T, Hächl O, Rudisch A, Ulmer H. Craniomaxillofacial trauma: a 10 year review of 9,543 cases with 21,067 injuries. J Craniomaxillofac Surg 2003; $31: 51-61$.

11. Statistical Portugal. Statistical Yearbook of Portugal. 2010-2011:11.

12. Thorén H, Snäll J, Salo J, Suominen-Taipale L, Kormi E, Lindqvist $\mathrm{C}$, et al. Occurrence and types of associated injuries in patients with fractures of the facial bones. American Associ Oral Maxillofac Surg. 2012; 68:805810.

13. Rhodes $G$. The evolutionary psychology of facial beauty. Annual Review Psychology 2006; 57:199-226.

14. Zarger M, Khajii A, Karbakhsh M, Zaraei MR. Epidemiology of facial injuries during 13 months of trauma registering in Tehran. $\mathrm{J}$ Med Ser 2004; 58(3):109-14

15. Khan M, Din UQ, Murad N, Shah SMA. Maxillofacial and associated fractures of the skeleton - A study. 
Pak Oral Dental J.2010; 30:313-16.

16. Punjabi SK, Khan M, Hassan QU, Nisa ZU. Associated Injuries with Facial Trauma - A Study J Liaquat Uni Med Heal Sci. 2012; 11:60-63

17. Zandi M, Seyed Hoseini SR. The relationship between head injury and facial trauma: a case-control study. Oral Maxillofac Surg. 2013; 17 (3):201-7.

18. Grant AL, Ranger A, Young GB, Yazdani A. Incidence of major and minor brain injuries in facial fractures. J Craniofac Surg. 2012; 23(5): 1324-8.

19. Ahmed S, Punjabi SK, Rehman HU, Aslam MA, Haider SM. Analysis of maxillofacial injuries spread over one year period in Karachi Sample. Pak Oral Dent J. 2014; 34: 50-53.

20. Hai-Hua Zhou, Qi Liu, Rong-Tao Yang, Zhi Li, Zu-Bing Li .Traumatic head injuries in patients with maxillofacial fractures: a retrospective case-control study. Dent Traumatolog. 2015; 31:209-1421.

21. Venugopal MG, Sinha R, Menon PS, Chattopadhyay PK, Roy Chowdhury SK. Fractures in the maxillofacial region: A four-year retrospective study. MJFAI 2010; 66:14-17

22. Rajendra PB, Mathew TP, Agrawal A, Sabharawal G. Characteristics of associated craniofacial trauma in patients with head injuries: An experience with 100 cases. J Emerg Trauma Shock. 2009; 2(2): 89-94.

23. Septa D, Newaskar VP, Agrawal D, Tibra S. Etiology, Incidence and Patterns of Mid-Face Fractures and
Associated Ocular Injuries. J Maxillofac Oral Surg. 2014; 13(2): 115-19.

24. Premchand $P$, Dange AK, A study of incidence and prevalence of Facial Fracture associated with fracture of Upper or Lower Limbs. J Cont Med A Dent.2016; 4: 19-21.

25. Ahmed S, Shaikh AH Punjabi SK, Ahmed S. Pattern of Maxillofacial injuries - A Study. Pak Oral Dent J. 2016; 36: 197-200.

26. ScherbaumEidt JM, De Conto F, De Bortoli MM, Engelmann JM, Rocha FD. Associated Injuries in Patients with Maxillofacial Trauma at the Hospital São Vicente de Paulo, Passo Fundo, Brazil. J Oral Maxillofac Res 2013; 4(3):e1

27. Thoren H, Johanna S, Salo J, Taipale L, Kormi E, Lindqvist $C$. Occurrence and types of associated injuries in patients with fractures of facial bones. $J$ Oral Maxillofacial Surg 2010; 68(4):805-10.

28. Beogo R, Dakoure P, Savadogo LB, Coulibaly AT, Ouoba K. Associated injuries in patients with facial fractures: a review of $\mathbf{6 0 4}$ patients. Panafrican Medical J. 2013; 16:1-5.

29. Obuekwe ON, Etetafia M. Associated injuries in patients with maxillofacial trauma. Analysis of 312 consecutive cases due to road traffic accidents. Peerreview J Biomed Sci. 2004; 3(1):30-6

30. Deliverska E. Occurrence and Types of Associated Injuries in Patients with Maxillofacial Fractures. Int J Sci Res (IJSR) 2014; 3(12):85-97.

\section{AUTHORSHIP AND CONTRIBUTION DECLARATION}

\begin{tabular}{|c|c|c|c|}
\hline Sr. \# & Author-s Full Name & Contribution to the paper & Author $=\mathbf{s}$ Signature \\
\hline 1 & Dr. Suneel Kumar Punjabi & Data collection \& Results & \\
\hline 2 & Dr. Altaf Ahmed Talpur & Concept \& Study Design & \\
\hline 3 & Dr. Abdul Rauf Memon & Discussion, Refereneces & \\
\hline 4 & Dr. Priya & $\begin{array}{l}\text { Intro, Abstract \& Proof } \\
\text { Reading }\end{array}$ & \\
\hline
\end{tabular}

